\title{
A Combined AHP and PROMETHEE Method for Selecting the LNG Receiving Terminal with Additional Safety Perspective
}

\author{
Putri Dyah Setyorini ${ }^{1,2, a, *}$, A.A.B. Dinariyana ${ }^{1,2, b}$ and Thariq A. Akbar ${ }^{1,2, c}$ \\ ${ }^{1}$ Department of Marine Engineering, Institut Teknologi Sepuluh Nopember, Surabaya, Indonesia \\ ${ }^{2}$ PUI KEKAL - Institut Teknologi Sepuluh Nopember, Surabaya, Indonesia \\ a.putridyahs@gmail.com,b.kojex@its.ac.id,c.thariqakb@gmail.com \\ *corresponding author
}

Keywords: $\quad$ LNG Receiving Terminal, AHP, PROMETHEE, Fire Modelling.

\begin{abstract}
In the purposes of reducing emission and as response to the global oil crisis, the Government of Indonesia is currently planning to convert some power plants and ships in Indonesia that is currently using fuel oil to be converted to natural gas (LNG). To fulfil the target, the infrastructure for LNG plant must be prepared such as an establishment of receiving terminal. One of the LNG receiving terminal that will be built in Indonesia is Makassar. The LNG receiving terminal in Makassar will be used as a hub to distribute gas to some power plants in the central part of Indonesia. Hence, this study proposes two stages of designing LNG receiving terminal. The first stage is to select the best alternatives of receiving terminal to be applied in Makassar. There are three alternatives namely: Floating Storage Unit (FSU) and Onshore Regasification; Floating Storage and Regasification Unit (FSRU); and Onshore LNG terminal. The second stage is to conduct the consequence analysis of the selected LNG receiving terminal by means of fire modelling. The selection of LNG receiving terminal in Makassar will be done using a combination of Preference Ranking Organization Method for Enrichment Evaluations (PROMETHEE) and Analytical Hierarchy Process (AHP). Since AHP has a good hierarchy structure, this method will be used as a weighting of criteria and sub-criteria. The weighting result of criteria and subcriteria from AHP process will be used for the ranking process using PROMETHEE, in this method the weighting will be multiplied with the alternatives preferences. A combination of both methods concluded that FSRU (Floating Storage and Regasification Unit) has the first rank, it means that FSRU will be applied as a LNG receiving terminal. After the selection process, the consequence analysis as well as fire modelling are conducted to assure that FSRU is safe. From the modelling, it can be concluded that only jetty and FSRU itself that will be affected by the fire event both jet fire and explosion.
\end{abstract}

\section{Introduction}

Consumption of electricity in Indonesia from the year 2000 to 2016 are increasing with an average of 6.8\% per year. From the RUPTL-PLN (Rencana Usaha Penyediaan Tenaga Listrik- Perusahaan Listrik Negara) report as well as electricity supply business plan that provided by State Electricity 
Corporation, it is reported that there are some plans to develop 50 PLTG/ MG for some regions in the Central part of Indonesia namely Kalimantan, Sulawesi and Nusa Tenggara region. The development is intended to fulfil the increasing demand for electricity in that region. Nationally, the addition of 1 unit of electricity infrastructure has an effect of $0.83 \%$ on economic growth. With the development of power plants in Central part of Indonesia, it must be supported by the receiver terminal that will be placed in Makassar. Your paper will be part of the journals therefore we ask that authors follow the guidelines explained in this example, in order to achieve the highest quality possible.

\section{LNG Receiving Terminal Selection}

This section discussed the selection process of the types of LNG receiving terminal. The selection process was done by using a combination of MCDM method (Multi Criteria Decision Making) namely Analytical Hierarchy Process (AHP) and Preference Ranking Organization Method for Enrichment Evaluations (PROMETHEE). MCDM is a decision-making technique of some alternatives that exist based on certain criteria [1]. Some examples of methods that include MCDM are Analytical Hierarchy Process (AHP) [2], Preference Ranking Organization Method for Enrichment Evaluation (PROMETHEE) [3], Technique for Order Preference by Similarity to Ideal Solution (TOPSIS), Elimination of Et Choix Traduisant la Realite (ELECTRE) [4], and several methods. In this study, the AHP and PROMETHEE are combined as a method for the selection process. There are some researches that already using a combined AHP-PROMETHEE, for the example the research from Lemantara [5] and by some researcher [6]-[8]. By using Lemantara's research as the reference, the framework for thinking of the selection process can be seen in Figure 1.

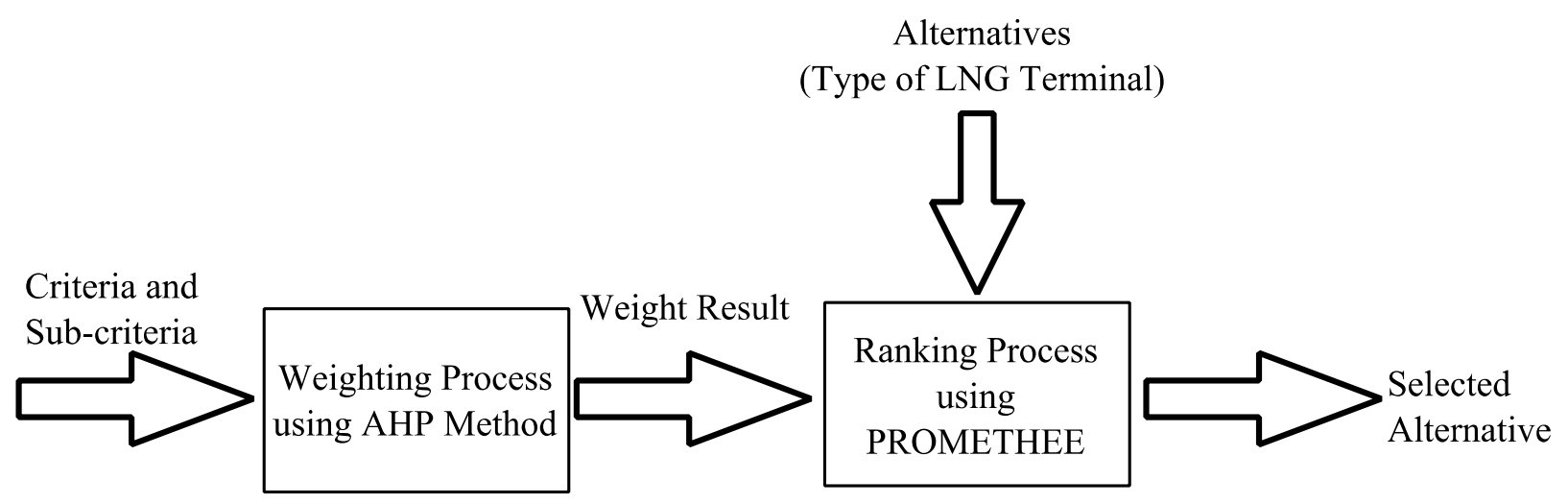

Figure 1: Framework for Thinking of AHP-PROMETHEE.

From the Figure 1, it can be seen that the first process starts from AHP method using criteria and sub-criteria as input, AHP will do the weighting process against the criteria and sub-criteria that already determined. Weights that obtained from the AHP process are used as input for ranking processes with PROMETHEE method. The PROMETHEE method will rank each alternative from the types of LNG receiving terminal. With AHP and PROMETHEE processes an alternative priority will be obtained, so alternatives can be selected according to the priority. 


\subsection{Weighting Process using AHP Method}

There are some steps that should be done for the weighting process using AHP, such as:

1) Criteria for Selecting the Types of LNG Receiving Terminal

To select the best option of LNG receiving terminal, several criterions are required to be used as an assessment parameter for each given concept of LNG receiving terminal. There are 5 criterions that will be used for LNG receiving terminal selection process, namely: cost; technical; social; safety; and operational. Then from the criteria that already determined, the sub-criteria must be determined for each criterion. Some of the sub-criteria such as: environmental conditions; ease of offloading; technology; investment; operational and maintenance costs; development time; public safety; environmental impact; accessibility; licensing; and operational ease.

2) Alternatives for Selecting the Types of LNG Receiving Terminal

In addition to criteria and sub-criteria, the concept LNG receiving terminal also need to be determined as alternatives. There are 3 concepts/ alternatives that will be used in this study, namely:

1. FSU (Floating Storage Unit) and Onshore Regasification Unit

2. FSRU (Floating Storage and Regasification Unit)

3. Onshore LNG terminal

The three concepts of the LNG receiving terminal that already determined are used as alternatives to be selected for receiving terminal in Makassar.

3) Hierarchy Arrangement

Information on the selection of LNG receiving terminal types such as criteria, sub-criteria, and alternatives has been established for the hierarchy arrangement. The arrangement of the hierarchy is one of the stages in the AHP method that aims to structuralize the existing problems. The several levels used in constructing a hierarchy are described in the following explanation:

- First Stage

At this level contains the objectives of the problem to be achieved. In this study, the objective to be achieved is to select the type of LNG receiving terminal according to the criteria and sub-criteria that have been set as parameters.

- Second Stage

At the second level contains what parameters that affect in achieving the goal. These parameters are the criteria used to determine the type of LNG receiving terminal to be applied. Some of these criteria are namely: cost; technical; social; safety; and operational.

- Third Stage

This third level is the last level in the process of hierarchy. At this level contains concepts to be used as alternatives in the selection. The alternative is the concepts that will be applied as the LNG receiving terminal in Makassar.

With an explanation of levels, the following of a hierarchical illustration can be seen in Figure 2 . 


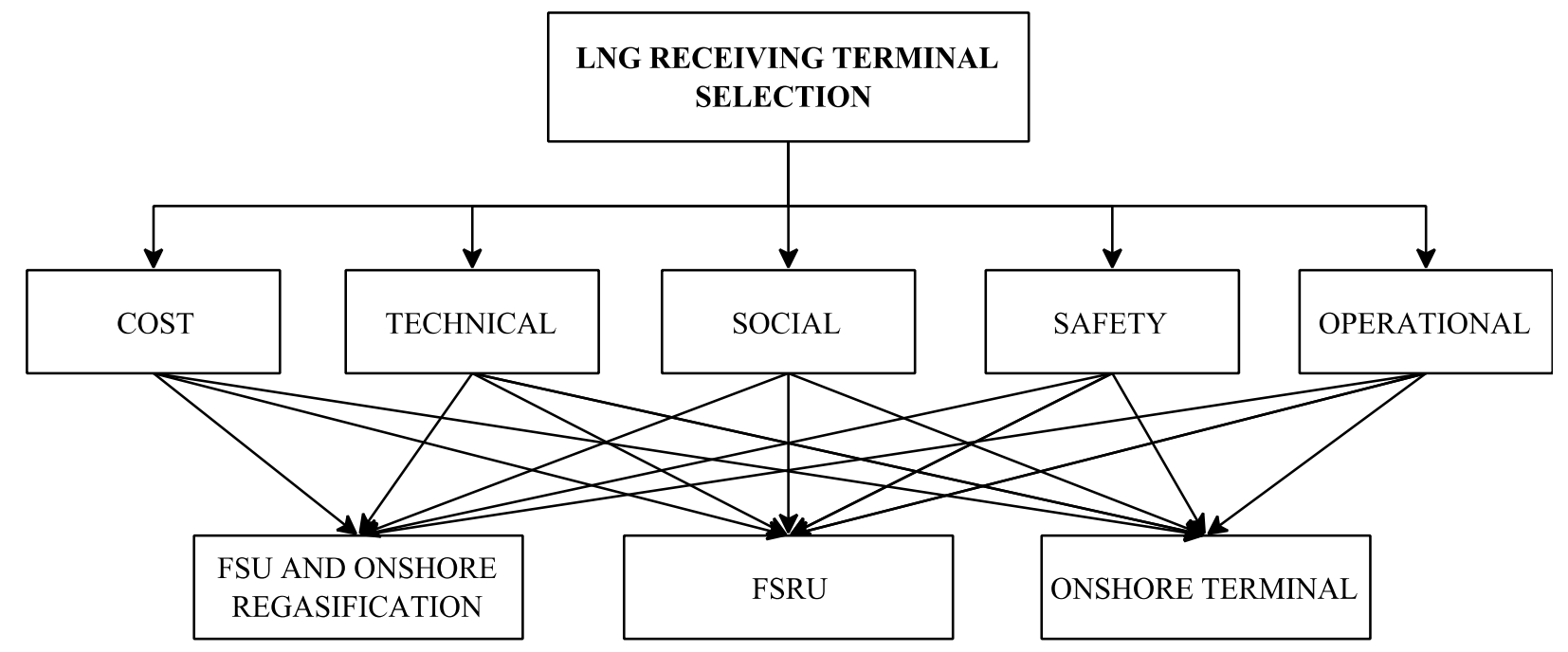

Figure 2: Structure of Hierarchy in the Selection Process of LNG Receiving Terminal.

4) Weighting Process using Expert Choice

With reference to the election hierarchy that has been determined, then made the questionnaire. With the questionnaire, it will be given to some expert judgment to conduct the assessment. After the assessment by the expert judgment, then with the help of Expert Choice obtained the weight of each criterion that can be seen on Table 1.

Table 1: The Result of Weighting for Each Criteria Using AHP Method

\begin{tabular}{llll}
\hline No & Criteria & Weight & Percentage \\
\hline 1 & Cost & 0.227 & $23 \%$ \\
2 & Technical & 0.070 & $7 \%$ \\
3 & Social & 0.250 & $25 \%$ \\
4 & Safety & 0.343 & $34 \%$ \\
5 & Operational & 0.109 & $11 \%$ \\
\hline
\end{tabular}

\subsection{Rank Process using PROMETHEE Method}

By weighting using the AHP method, the next step in determining the LNG receiving terminal is by performing the ranking process using the PROMETHEE method. Some steps to be done on this ranking process [9], namely:

1) Defining Preferences and Parameters

The preference aims to provide a better description of unequal areas, used the function of the criteria value between the alternatives $H$ (d) where this has a direct relationship to the function preference (p) and indifference (q). For the assessment principle is determined by the type of criterion, for example on the cost criteria, the preferred is the minimal value. The appropriate criteria type for each criterion is obtained by using the maximization or minimization function. The determination of the parameters and types of preferences that used for LNG receiving terminal selection can be seen on Table 2 .

2) Partial Ranking using PROMETHEE I

There are some steps for ranking process that should be done, such as: 
a. Defining Value of Preference

The value of preference $P$ was done by evaluating the deviation value (d) which is the value of the difference between alternative one with other alternatives to parameters ( $q$ and $p$ ). From the Table 3, it can be seen the assessment of each criterion against alternatives provided by expert judgment.

Table 2: The Result of Weighting for Each Criteria Using AHP Method.

\begin{tabular}{llccll}
\hline \multirow{2}{*}{ No } & Criteria & \multirow{2}{*}{$\begin{array}{c}\text { Type of } \\
\text { Preferences }\end{array}$} & $\begin{array}{c}\text { Principle } \\
(\text { Max/Min })\end{array}$ & \multicolumn{2}{c}{ Parameter } \\
\cline { 5 - 6 } & & $\mathrm{V}$ & Minimizing & 0.0 & $\mathrm{p}$ \\
\hline 1 & Cost & $\mathrm{V}$ & Maximizing & 0.0 & 2.7 \\
2 & Technical & $\mathrm{V}$ & Maximizing & 0.0 & 2.0 \\
3 & Social & $\mathrm{V}$ & Maximizing & 0.0 & 1.5 \\
4 & Safety & $\mathrm{V}$ & Maximizing & 0.0 & 1.0 \\
5 & Operational & & &
\end{tabular}

Table 3: Assessment Result of The Criteria Against the Alternatives

\begin{tabular}{ccccc}
\hline & & \multicolumn{3}{c}{ Alternatives } \\
\cline { 3 - 5 } & & $\begin{array}{c}\text { FSU-ONSHORE } \\
(\text { A1) }\end{array}$ & FSRU (A2) & $\begin{array}{c}\text { ONSHORE } \\
\text { TERMINAL (A3) }\end{array}$ \\
\hline \multirow{2}{*}{} & Cost & 3.3 & 4 & 2.3 \\
& Technical & 3 & 3.7 & 5 \\
.0 & Social & 3.5 & 4 & 3 \\
& Safety & 3 & 4 & 2.5 \\
& Operational & & 4 & 3 \\
\hline
\end{tabular}

By using Table III as references, the value of the preferences can be calculated. For example, the calculation of the preference value for cost criterion on alternative A1 (FSU - Onshore Terminal) to A2 (FSRU) by using the type of preference $\mathrm{V}$ with the formula 1 as follows:

$$
P=\left\{\begin{array}{c}
0, d \leq 0 \\
\frac{d-0}{2-0}, 0<d \leq 2 \\
1, d>2
\end{array}\right.
$$

For example, the value of cost criteria on A1 to A2 obtained the difference of value $d=0.7$ so that by following formula 1 , then calculated with, the value of preference is 0.35 . Another example with the same criteria that is for alternative A2 to A1 obtained the difference in value $d=-0.7$, so that if following the rules in formula 1, the value of preference for cost criteria on A1 to A2 is 0 .

The calculation was done on all criteria against each an alternative comparison to get a summary of the preference values that can be seen in Table 4 . 
Table 4: The Summary of The Value of Preference

\begin{tabular}{cccccc}
\hline \multirow{2}{*}{ fi (...,...) } & Cost & Technical & Social & Safety & Operational \\
\cline { 2 - 6 } & Type V & Type V & Type V & Type V & Type V \\
\hline A1-A2 & 0.00 & 0.00 & 0.00 & 0.00 & 0.00 \\
A2-A1 & 0.35 & 0.33 & 0.50 & 0.25 & 0.50 \\
A2-A3 & 0.85 & 0.00 & 0.75 & 0.75 & 0.00 \\
A3-A2 & 0.50 & 0.00 & 0.00 & 0.50 & 0.00 \\
A1-A3 & 0.50 & 0.00 & 0.50 & 0.50 & 0.00 \\
A3-A1 & 0.00 & 1.00 & 0.00 & 0.00 & 0.00 \\
\hline
\end{tabular}

b. Calculate the Index Preference

The preference values that have been obtained will be calculated as a whole by multiplying them on the weights of each criterion. This weighting value is obtained from the result of AHP process that has been done previously. The formula for calculate the index preference can be seen in formula 2 .

$$
\pi(a, b)=\sum_{j=1}^{k} w_{j} \cdot P_{j}(a, b)
$$

Herewith the summary of the index preference for all criteria of each alternative that can be seen in Table 5.

Table 5: The Summary of The Value of Preference

\begin{tabular}{ccccccc}
\hline $\mathbf{f i}$ & Cost & Technical & Social & Safety & Opertaional & $\begin{array}{c}\text { Index } \\
\text { Preference }\end{array}$ \\
\cline { 2 - 6 } (...,...) & Type V & Type V & Type V & Type V & Type V & 0.00 \\
\hline A1-A2 & 0.00 & 0.00 & 0.00 & 0.00 & 0.00 & 0.37 \\
A2-A1 & 0.35 & 0.33 & 0.50 & 0.25 & 0.50 & 0.64 \\
A2-A3 & 0.85 & 0.00 & 0.75 & 0.75 & 0.00 & 0.29 \\
A3-A2 & 0.50 & 0.00 & 0.00 & 0.50 & 0.00 & 0.52 \\
A1-A3 & 0.50 & 0.00 & 0.50 & 0.50 & 0.00 & 0.07 \\
A3-A1 & 0.00 & 1.00 & 0.00 & 0.00 & 0.00 & \\
Weight & $\mathbf{0 . 2 3}$ & $\mathbf{0 . 0 7}$ & $\mathbf{0 . 2 5}$ & $\mathbf{0 . 3 4}$ & $\mathbf{0 . 1 1}$ & \\
\hline
\end{tabular}

c. Calculation of Outranking Flow

At this stage will be calculate positive and negative value of outranking flow to find the best alternative. Leaving flow can be regarded as the strength and entering flow as the weakness of one alternative to other alternatives. The value of leaving flow and entering flow comes from the preference index calculation that has been done before. The formula of leaving flow can be seen in formula 3, meanwhile the entering flow can be seen in formula 4.

$$
\begin{aligned}
& \phi^{+}=\frac{1}{n-1} \sum_{x \in A} \varphi(a, x) \\
& \phi^{-}=\frac{1}{n-1} \sum_{x \in A} \varphi(x, a)
\end{aligned}
$$


Herewith the summary of leaving flow and entering flow of each alternatives can be seen in Table 6.

Table 6: The Summary of Entering Flow and Leaving Flow

\begin{tabular}{lllll}
\hline ALTERNATIVES & A1 & A2 & A3 & Leaving Flow \\
\hline A1 & 0.00 & 0.00 & 0.52 & $\mathbf{0 . 2 6}$ \\
A2 & 0.00 & 0.00 & 0.64 & $\mathbf{0 . 3 2}$ \\
A3 & 0.07 & 0.29 & 0.00 & $\mathbf{0 . 1 8}$ \\
Entering Flow & $\mathbf{0 . 0 2}$ & $\mathbf{0 . 0 7}$ & $\mathbf{0 . 2 9}$ & \\
\hline
\end{tabular}

3) Complete Ranking using PROMETHEE II

At this stage is the last process of the ranking process using PROMETHEE method. The stage is complete ranking process for the all alternatives, namely net flow calculation. Net flow value comes from the calculation of the difference value of leaving flow and entering flow. The formulation for calculating the net flow can be seen in formula 5.

$$
\phi(a)=\phi^{+}(a)-\phi^{-}(a)
$$

Herewith the summary of net flow and the result of the ranking for all alternatives can be seen on Table 7.

Table 7: The Summary and Ranking Result.

\begin{tabular}{lllll}
\hline Alternatives & Leaving Flow & Entering Flow & Net Flow & Ranking \\
\hline A1 & 0.26 & 0.02 & 0.24 & 2 \\
A2 & 0.32 & 0.07 & 0.25 & 1 \\
A3 & 0.18 & 0.29 & -0.11 & 13 \\
\hline
\end{tabular}

From the Table 7, it can be concluded that the selected type of LNG receiving terminal is alternative A2, the alternative that using FSRU concept will be applied as LNG receiving terminal in Makassar.

\section{Consequence Analysis}

The concept of a FSRU has been selected and proposed as an alternative to LNG receiving terminal in Makassar. With FSRU concept, Sohn et al. in their study says that FSRU has an advantage such as the risk to the public is negligible [10]. It is also worth noting that an accident in one onshore plant might produce considerable impact on the neighbouring areas and their population [11]. There are some researchers who compare the areas impacted by undesired events in onshore and offshore terminals in addition to possible consequences of LNG leakages [12], [13].

The proposed location of FSRU as LNG receiving terminal in Makassar can be seen in Figure 3. As we can see in Figure 3, the FSRU will be moored to the jetty and accommodated by $1.000 \mathrm{~m}$ of trestle in order to fulfil the draught of FSRU. 


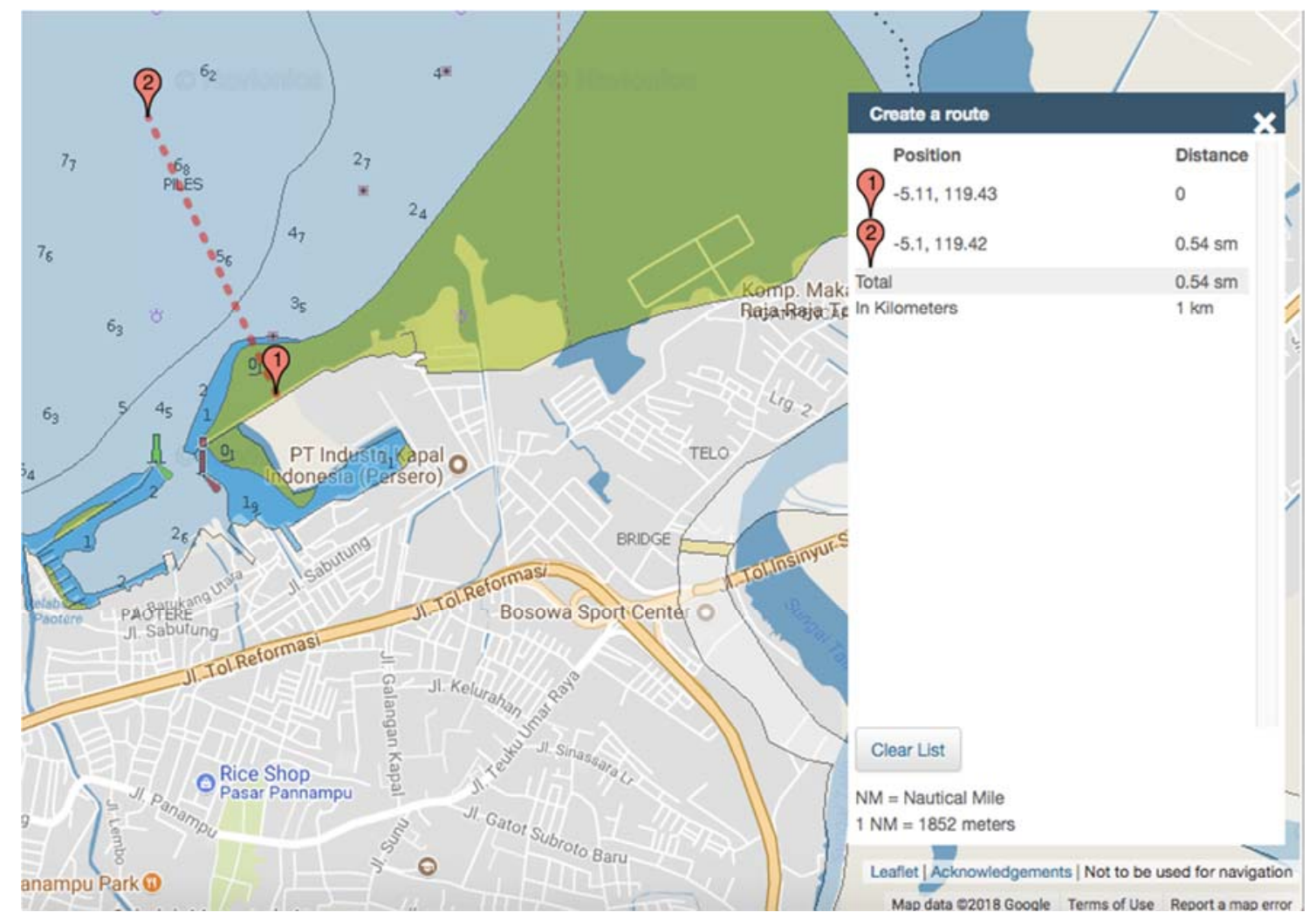

Figure 3: The Proposed Location of FSRU in Makassar [14].

The consequence modelling must be carried out despite of the proposed location of FSRU is far enough from the population in onshore area. As we all know, the major concern regarding the hydrocarbon facility such as FSRU is the effect of unintended release and flammable event of the hydrocarbon.

Mostly, some papers will discuss a complete quantitative risk analysis. The risk analysis was conducted based on the Formal Safety Assessment (FSA) proposed by the International Maritime Organization [15]. The process of FSA started from defining the problem, followed by the identification of hazards, using the preliminary hazard analysis technique (PHA). Later, a risk analysis was conducted by investigating the frequency of occurrence and possible consequences of the identified potential hazardous scenarios; finally, effective and practical risk control options were proposed [11]. But in this paper, the addition safety perspective will only discuss about consequence analysis.

Generally, the consequences modelling is a part of Quantitative Risk Analysis (QRA) to determine the consequences in respect of the risk representation, since the method to determine the result is based on numerical approach to calculate the corresponding events. In operational which involving a lot of person exposed the effects, the events which lead into fatality or live loss are contribute to an individual and the societal risk in the site's surrounding. Individual risk regarding this case are divided into 2 parties, which 1st parties is the operator of the FSRU which have direct contact with the FSRU and 3rd party is the non-personnel who does not involve at all with the operation and offsite population expressed as the fatality risk due to exposure. 


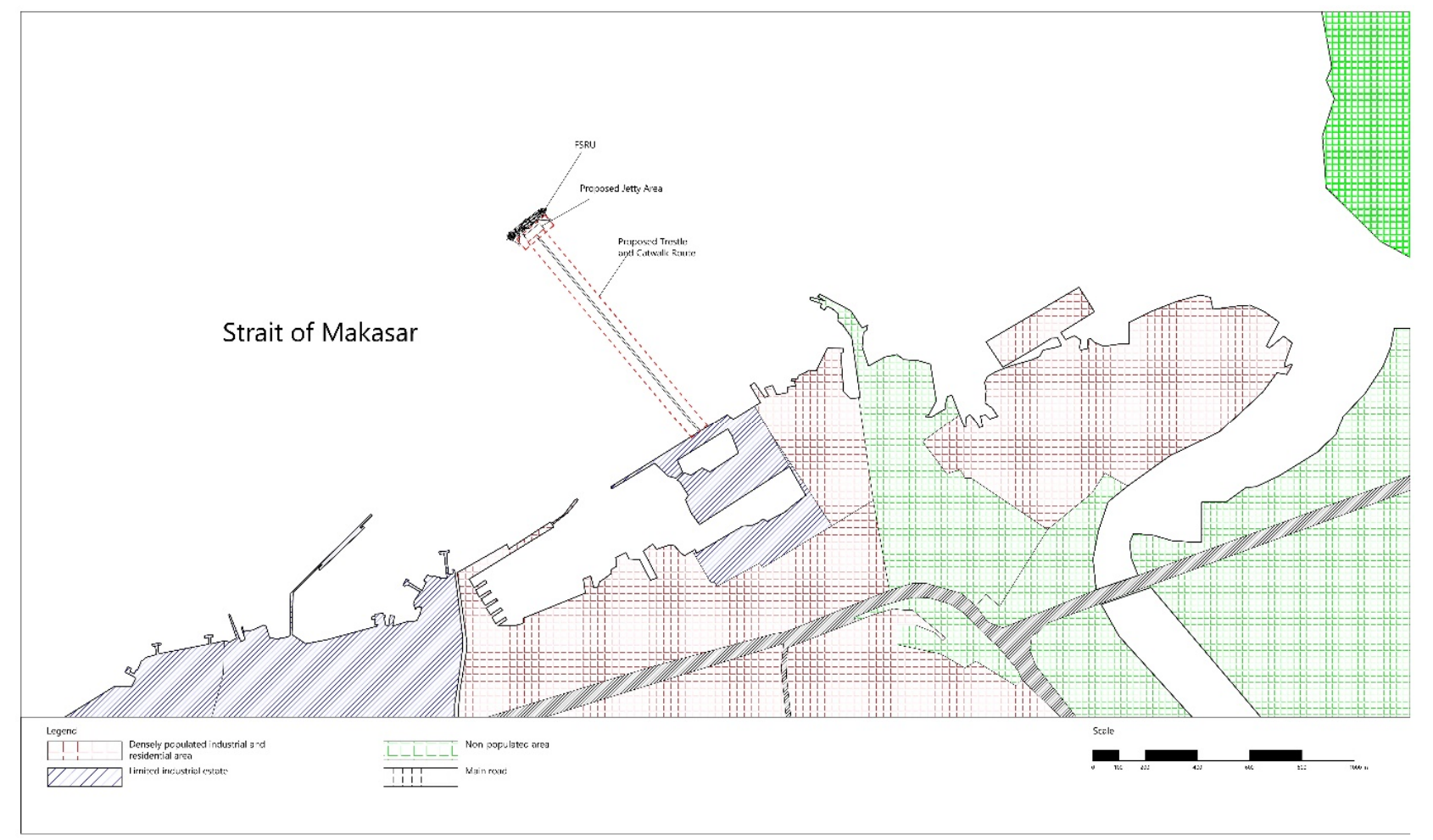

Figure 4: Layout of the FSRU area

As illustrated in Figure 4, densely populated consist of industrial and residential area which leads to high causalities if exposed by the flammable event. The red area showed the typical area of densely populated residential and industrial estate, the blue area showed limited access of industrial area and the green area define free space or non-populated area.

There are some certain limitation were applied regarding of the consequences analysis on this case, such as:

1) The consequences that will be performed only the flammable events which is Jet fire and explosion.

2) The variations of Jet Fire were considering the bore leak diameter at $50 \mathrm{~mm}$ and $150 \mathrm{~mm}$ leak,

3) The variations of the most appear wind directions and speed based on 20 years historical wind data showed in Figure 5 [16].

4) Due to unavailability of the detailed design of the FSRU, the location of the release are assumed on the manifold, which have critical role in transfer system, and the explosion which could occur on the cargo tanks of the FSRU. 


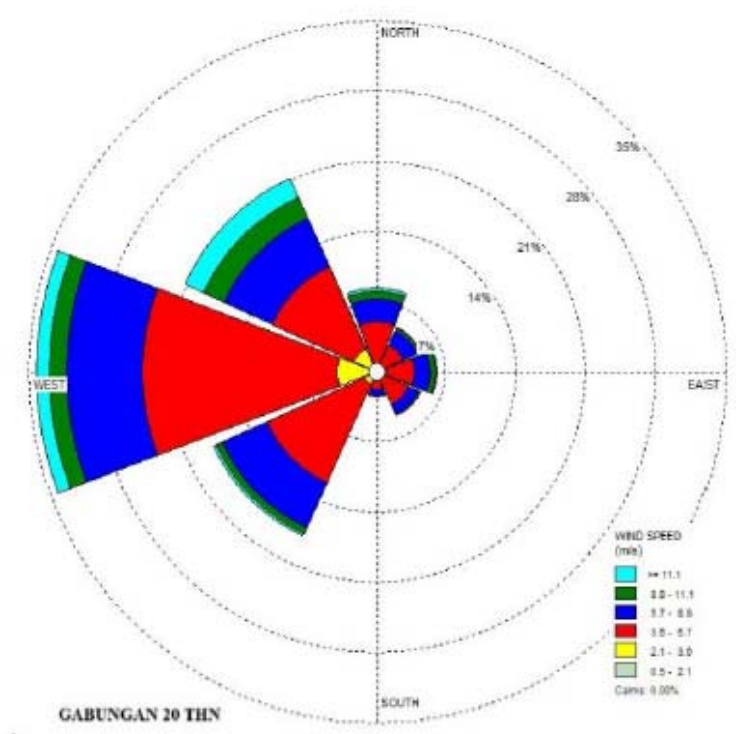

Figure 5. Wind Rose Diagram Port of Makassar

The result for consequences modelling for Jet Fire Scenario for bore leak $50 \mathrm{~mm}$ for each direction of wind are showed on Figure 6. It shows that the effect of Jet Fire at worst scenario only affected the area of the jetty or otherwise it does not affect the shore area. The result also shows that the consequence does not much affected by the wind speed and direction.
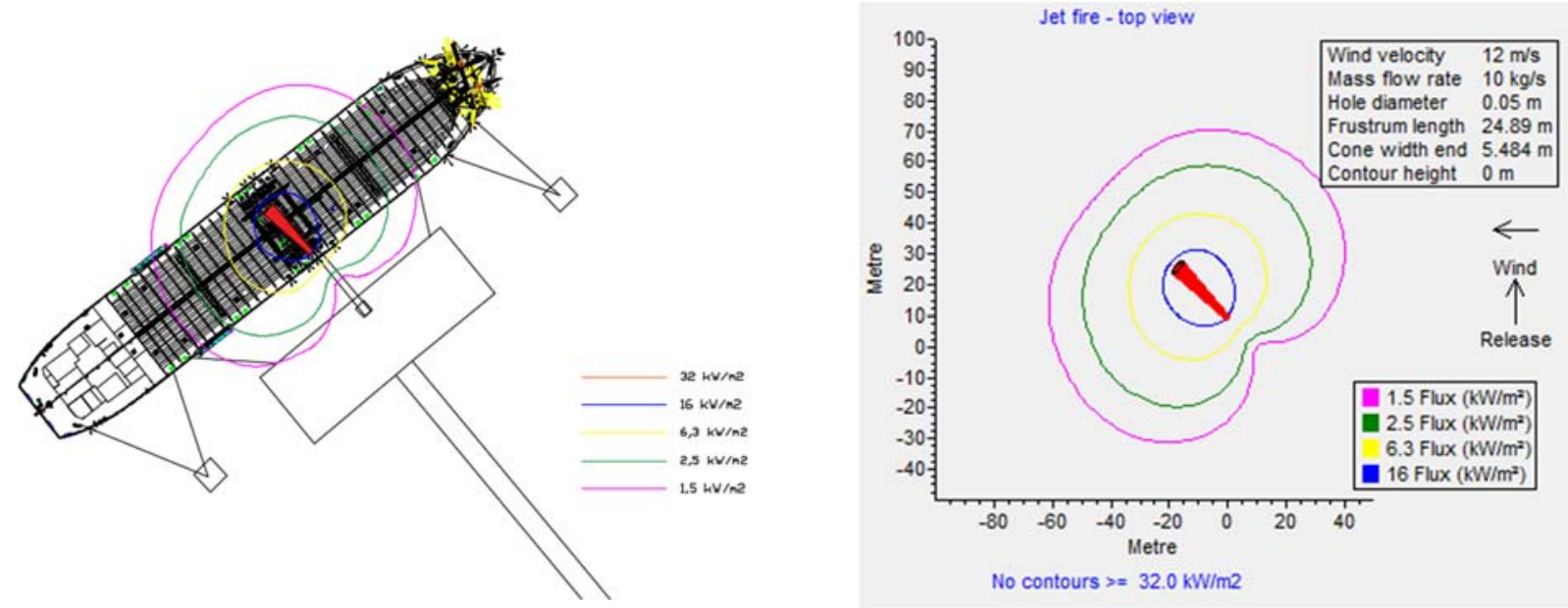

(a) 

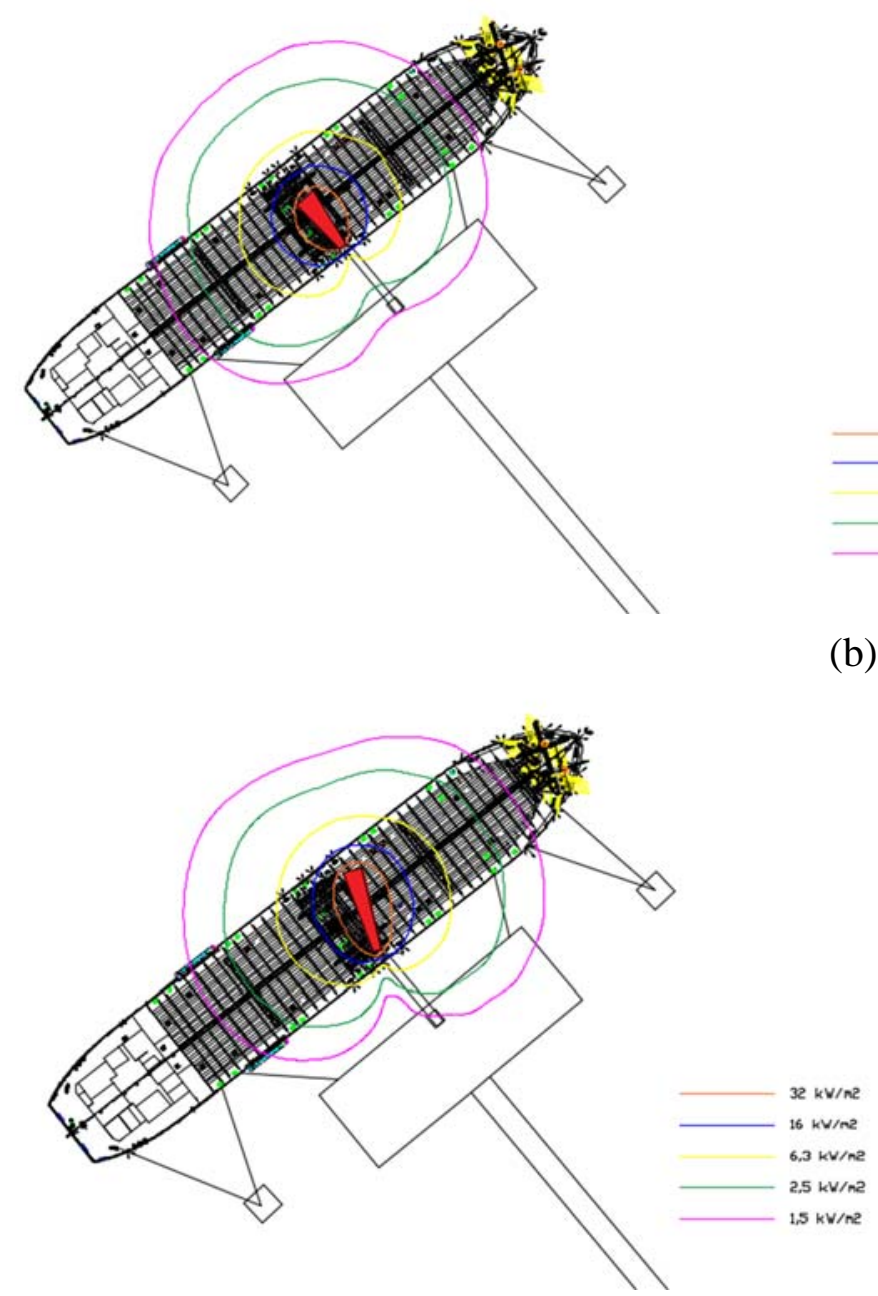

(b)

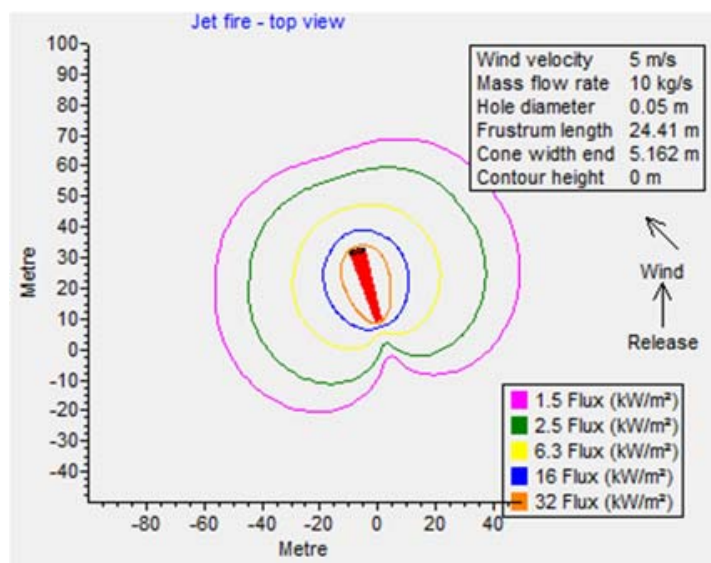

(c)

Figure 6: Result for Jet Fire 50 mm Bore Leak Scenario, (a) for Wind Direction to West, (b) Southwest, and (c) Northwest

For the Jet Fire scenario at bore size diameter $150 \mathrm{~mm}$ showed on Figure 7. Theoretically, the effect of $50 \mathrm{~mm}$ bore leak are lower than the $150 \mathrm{~mm}$ bore leak scenario.
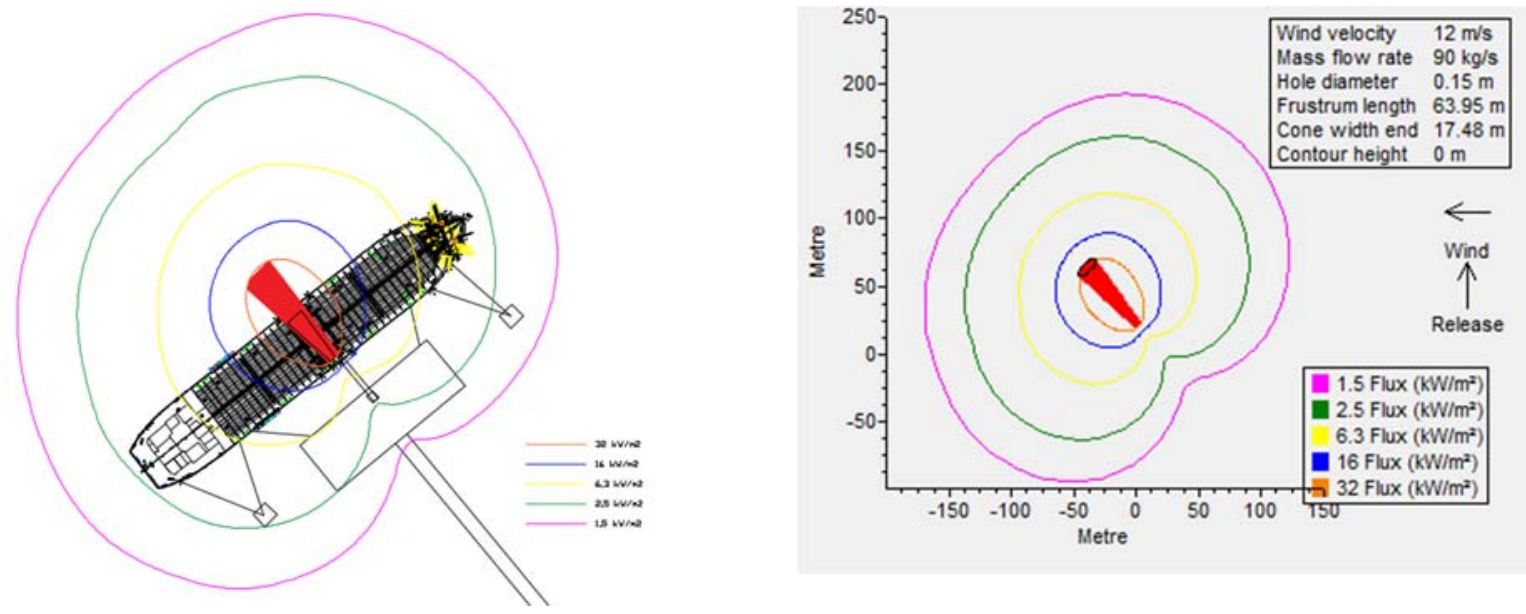

(a) 


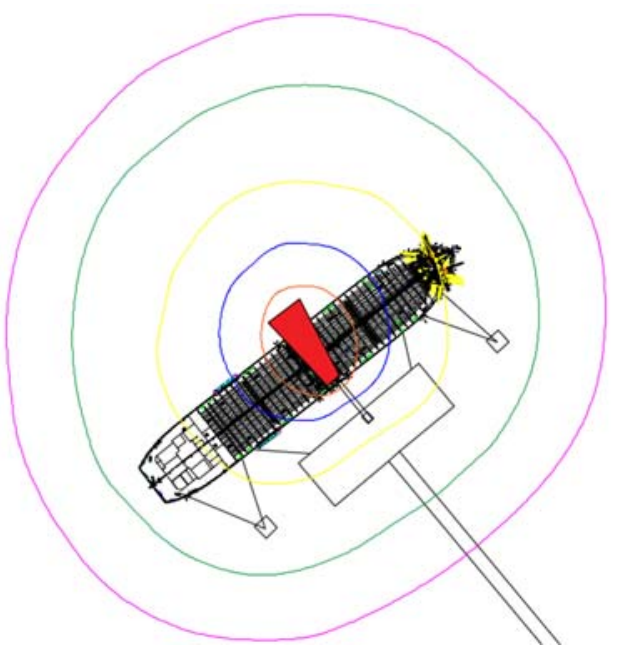

$=$

(b)
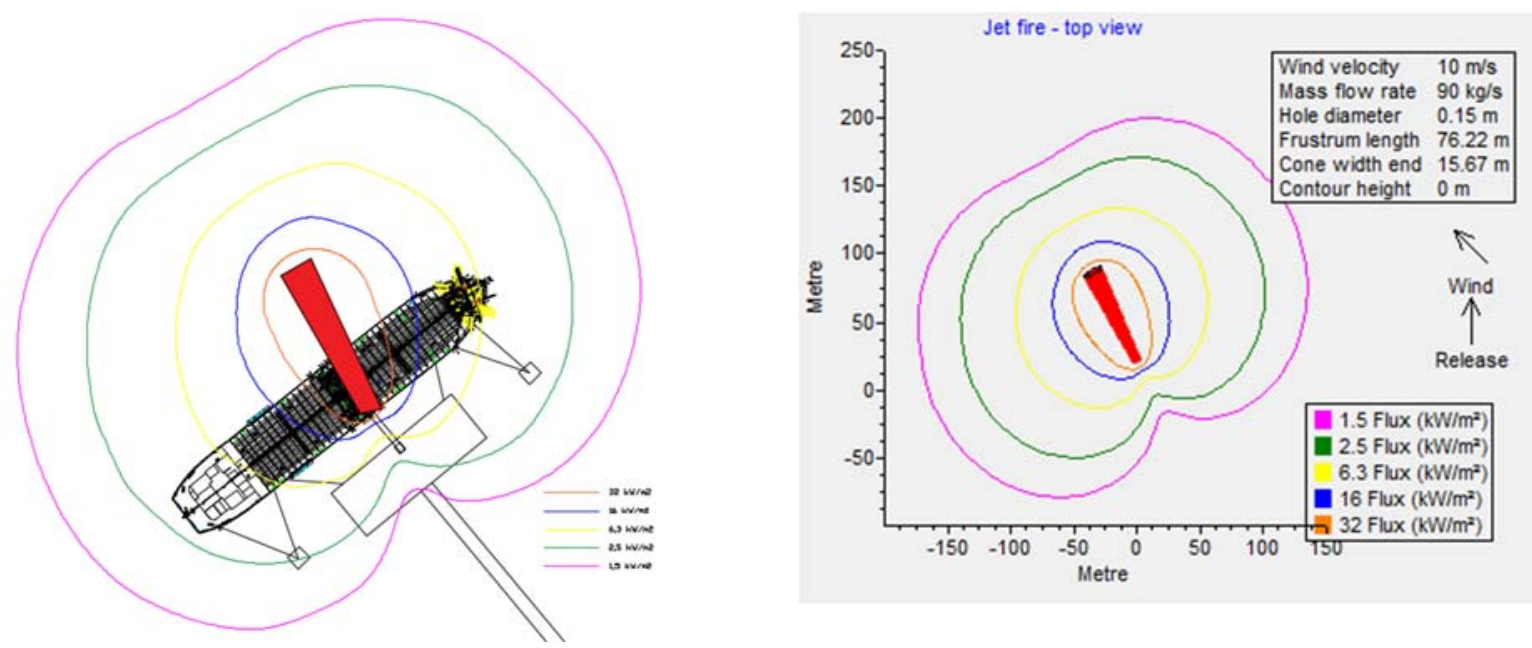

(c)

Figure 7: Result of Jet Fire 150 mm bore leak scenario (a) for Wind Direction to West, (b) Southwest, and (c) Northwest.

For tank explosion scenario showed in Figure 8 it can be seen that the result showed the affected area only in the FSRU and jetty.
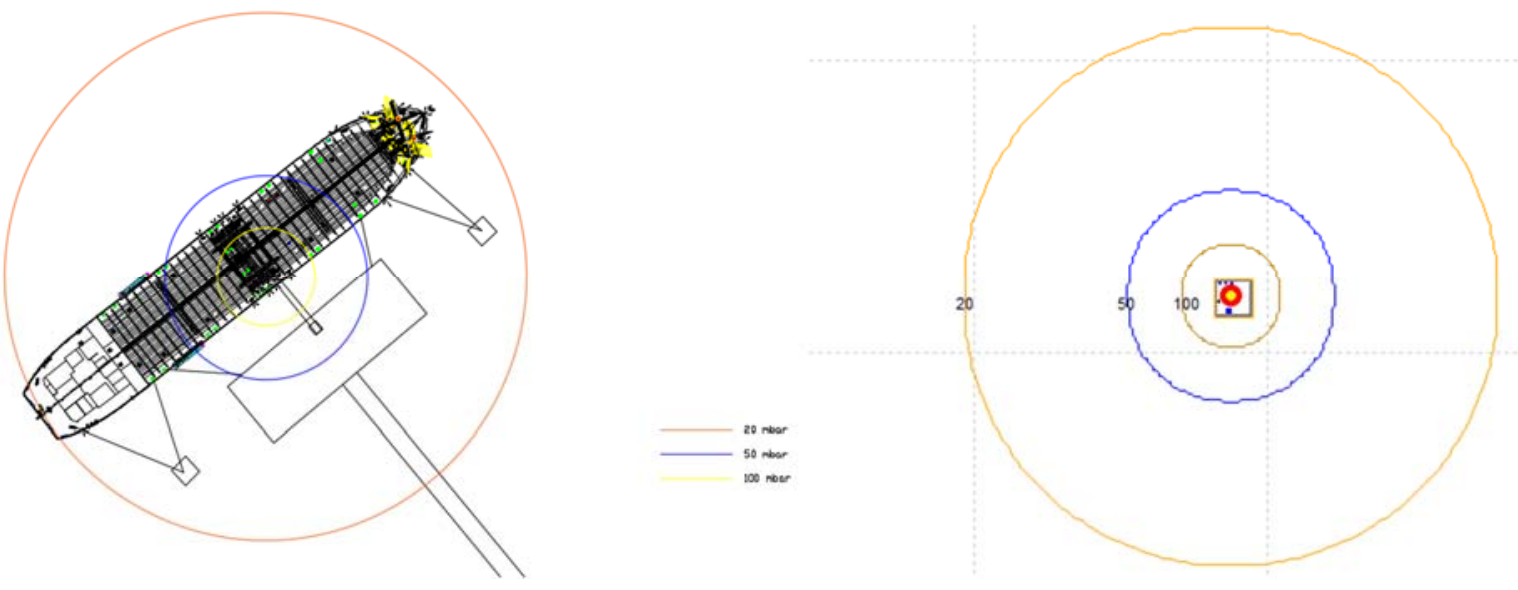

Figure. 8: Result of Explosion. 


\section{Conclusions}

This study concluded two conclusions, the first one is about the selection study of LNG receiving terminal and the second one is about the consequence analysis. For the selection study of LNG receiving terminal, a combined AHP and PROMETHEE method are applied. Each method has an advantages and disadvantages, the AHP method is good for the structure process because AHP have a good hierarchy concept, so the weighting process was done using AHP. Meanwhile PROMETHEE method has a good outranking process, so the rank process was done using PROMETHEE. From the combined AHP-PROMETHEE method, it can be concluded that FSRU is the selected concept that will be located in Makassar. In this paper, additional safety perspective only carried the consequence analysis. The consequence analysis as well as fire modelling was carried out to assure that the FSRU facilities are safe. Individual risk regarding this case are divided into 2 parties, which the 1st party is the operator of the FSRU which have direct contact with the FSRU and the 3rd party is the non-personnel who does not involve at all with the operation and offsite population expressed as the fatality risk due to exposure. From the modelling, it can be concluded that only jetty and FSRU itself that will be affected by the fire event both jet fire and explosion.

\section{References}

[1] J. Rahardjo, R. E. Stok, and R. Yustina, "Penerapan Multi-Criteria Decision Making Dalam Pengambilan Keputusan Sistem Perawatan,” J. Tek. Ind., vol. 2, pp. 1-12, 2000.

[2] M. I. I. Auliya Rahmayani, "Perancangan dan Implementasi Perangkat Kriteria Menggunakan Metode AHP,” J. Sains dan Seni ITS, vol. 5, no. Sistem Pendukung Keputusan, 2016.

[3] S. Zhaoxu and H. Min, "Multi-Criteria decision making based on PROMETHEE method," in International Conference on Computing, Control and Industrial Engineering, 2010, pp. 2-4.

[4] E. Khamehchi, M. Khishvand, and H. Abdolhosseini, "A case study to optimum selection of deliquification method for gas condensate well design: South Pars gas field,” Ain Shams Eng. J., vol. 7, no. 2, pp. 847-853, 2016.

[5] J. Lemantara, N. A. Setiawan, and M. N. Aji, "Rancang Bangun Sistem Pendukung Keputusan Pemilihan Mahasiswa Berprestasi Menggunakan Metode AHP dan Promethee," J. Nas. Tek. Elektro dan Teknol. Inf., vol. 2, no. 4, pp. 20-28, 2013.

[6] A. Singh, A. Gupta, and A. Mehra, "An AHP-PROMETHEE II method for 2-tuple linguistic multicriteria group decision making," in Reliability, Infocom Technologies and Optimization (ICRITO) (Trends and Future Directions), 2015 4th International Conference, 2015.

[7] M. Behzadian, R. Samizadeh, and J. Nazemi, "Decision making in house of quality: A hybrid AHP-PROMETHEE approach," in IEEM2010 - IEEE International Conference on Industrial Engineering and Engineering Management, 2010, pp. 930-934.

[8] S. G. Kamble, K.Vadirajacharya, and U. V. Patil, "Decision Making in Distribution System using improved AHPPROMETHEE method," in Proceedings of the IEEE 2017, 2017, no. International Conference on Computing Methodologies and Communication (ICCMC), pp. 1-5.

[9] J. P. Brans and P. Vincke, "A Preference Ranking Organisation Method: (The PROMETHEE Method for Multiple Criteria Decision-Making),” Manage. Sci., vol. 31, no. 6, pp. 647-656, 1985.

[10] Y. Sohn, S. Kim, and I. Yoon, "Conceptual Design of LNG FSRU Topside Regasification Plant," The Twentysecond International Offshore and Polar Engineering Conference. International Society of Offshore and Polar Engineers, Rhodes, Greece, 2012.

[11] M. R. Martins, M. A. Pestana, G. F. M. Souza, and A. M. Schleder, "Quantitative risk analysis of loading and offloading liquefied natural gas (LNG) on a floating storage and regasification unit (FSRU)," J. Loss Prev. Process Ind., vol. 43, pp. 629-653, 2016.

[12] M. A. Ramos, E. L. Droguett, M. R. Martins, and H. P. Souza, "Quantitative Risk Analysis and Comparison for Onshore and Offshore LNG Terminals: The Port of Suape - Brazil Case," Vol. 2 Struct. Saf. Reliab., no. November 2017, pp. 885-892, 2011.

[13] M. Ramos, E. L. Droguett, M. Martins, and H. Souza, "Comparison of Possible Consequences of LNG Leakages in Offshore and Onshore Terminals : the Case of the Port of Suape,” no. June 2013, pp. 40-49, 2014. 
[14] SVB GmbH, “Portmaps," 2018. [Online]. Available: https://www.portmaps.com/eng/Map.

[15] IMO, "Revised Guidelines for Formal Safety Assessment (FSA) for use in the IMO Rule-making Process, ” London, 2013.

[16] F. Rabung, A. B. Muhiddin, M. P. Hatta, and S. Malik, “Deformasi gelombang di pantai makassar,” in Hasil Penelitian Teknologi Terapan, 2015, vol. 9, no. May 2016, pp. 978-979. 